\title{
Theism, Possible Worlds, and the Multiverse
}

\section{Klaas J. Kraay}

Ryerson University

digital.library.ryerson.ca/object/38

Please Cite:

Kraay, K. J. (2010). Theism, possible worlds, and the multiverse. Philosophical Studies, 147(3), 355-368.

doi:10.1007/s11098-008-9289-y

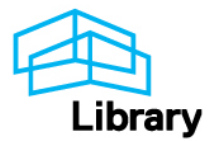




\title{
THEISM, POSSIBLE WORLDS, AND THE MULTIVERSE
}

\author{
Klaas J. Kraay \\ Ryerson University
}

This paper appears in Philosophical Studies 147 (2010): pp.355-368. The published version can be found online at: http://www.springerlink.com/content/821k362025475266/fulltext.pdf

God is traditionally taken to be a perfect being, and the creator and sustainer of all that is. So, if theism is true, what sort of world should we expect? To answer this question, we need an account of the array of possible worlds from which God is said to choose. It seems that either there is (a) exactly one best possible world; or (b) more than one unsurpassable world; or (c) an infinite hierarchy of increasingly better worlds. Influential arguments for atheism have been advanced on each hierarchy, and these jointly comprise a daunting trilemma for theism. In this paper, I argue that if theism is true, we should expect the actual world to be a multiverse comprised of all and only those universes which are worthy of creation and sustenance. I further argue that this multiverse is the unique best of all possible worlds. Finally, I explain how his unconventional view bears on the trilemma for theism.

\section{Possible WorldS AND THeir AXiOlogicAl Properties}

Theism (as I shall use the term) holds that there necessarily exists a being, God, who is unsurpassable in power, knowledge, and goodness, and who is the creator and sustainer of all that is. In contemporary analytic philosophy of religion, the role of creator and sustainer is construed like this: God surveys the set of possible worlds, and freely selects exactly one for actualization on the basis of its axiological characteristics. Discussions of this issue, then, typically assume that worlds have axiological status, and that they can (at least in principle) be evaluated: some are good, others are bad; some are better, others are worse. I will proceed on these assumptions.

Here is one way to understand the axiological status of possible worlds. Possible worlds are taken to be concrete objects by some, abstract objects by others, and convenient fictions by still others. But no matter which account is correct, it seems plausible to suppose that, if a world is actual, it can properly be said to bear world-good-making properties (hereafter WGMPs). These are properties which, ceteris paribus, tend to make worlds good. ${ }^{1}$ Similarly, it is reasonable to suppose that there are world-bad-making properties (hereafter WBMPs). ${ }^{2}$ On this account, the axiological status of a world can be understood to depend upon which WGMPs and WBMPs are instantiated in the world, and (for degreed properties) the degree to which they are exemplified. ${ }^{3}$

To simplify matters, let's assume necessitarianism: the actual set of WGMPs and WBMPs could not possibly have had different members than it does. ${ }^{4}$ And let's assume, again for simplicity, that all worlds are both commensurable and comparable with respect to these properties. 5 Finally, in what follows I restrict my focus to divinely-actualizable worlds. While it is tempting to assume that every possible world is capable of actualization by God, Alvin Plantinga has persuasively argued that this is false (1974a, 169-184). While I will not always explicitly qualify my discussion below to indicate this restriction, it should be presumed. 


\section{THREE HIERARCHIES OF ACTUALIZABLE WORLDS; THREE OBJ ECTIONS TO THEISM}

To properly consider God's choice of a world, something must be said about the vast array of worlds from which God is said to choose. The foregoing axiological considerations suggest that there are three candidate hierarchies of divinely-actualizable worlds worth considering. At most one of these can be correct, but for now, I'll treat each as a live option.

(1) Famously, Leibniz and others have held that there is exactly one unsurpassable world. (Hereafter, I'll call this view EOUW.)

(2) Other philosophers have held that there are multiple unsurpassable worlds. ${ }^{6}$ This view is generally supported by the thought that for any world $\mathrm{w}$ having axiological status $\mathrm{s}$, there is a trivially different variant, $\mathrm{w}^{\prime}$, that also has axiological status S.7 Moreover, it is often thought that there are infinitely many such variants. On this view (hereafter IMUW), there are infinitely many unsurpassable worlds.

(3) Still other philosophers, following Aquinas, ${ }^{8}$ have suggested that perhaps there are no unsurpassable worlds, but that instead there is an infinite hierarchy of increasingly better worlds. ${ }^{9}$ (Hereafter, I'll call this position NUW.)

Objections to theism have been leveled on each hierarchy:

(1) Famously, on EOUW it has been urged, a priori, that a perfect being would actualize the unique best world, and a posteriori, that this expectation has not been met. In short, it is claimed that the actual world is surpassable, and that this disconfirms theism. ${ }^{10}$

(2) It has been claimed that IMUW is inconsistent with theism: if there are infinitelymany unsurpassable worlds, God would not have sufficient reason to actualize any particular one. This would lead to "paralysis of the divine motivational system", which is inimical to theism. ${ }^{11}$

(3) Finally, it has been suggested that NUW precludes perfect being theism, since no matter which world a putatively-unsurpassable being actualizes, that being could be surpassed by a being who (all else equal) actualizes a better world. ${ }^{12}$

Since the three hierarchies are mutually exclusive and jointly exhaustive, ${ }^{13}$ these three objections constitute an unpalatable trilemma for theism. In Section 3, I clarify what is meant by God actualizing a world. In Sections 4 and 5, I introduce a special possible world - the theistic multiverse - and in Sections 6 and 7, I show how it bears on this trilemma. I urge that theists should maintain that the world God will actualize is the theistic multiverse, and I argue that it is the unique best of all divinely-actualizable worlds.

\section{WORLD-ACTUALIZATION}

Before proceeding, some clarifications about world-actualization are in order. When God selects a world for actualization, God causes it to be the case that one world rather than another is actual. It is sometimes tempting to imagine that, in so doing, (a) God stands outside the set of possible worlds; that (b) God always creates something; and that (c) God determines each and 
every feature of the ensuing world (d) all at once. The first two assumptions are false, and the latter two are dispensable on theism.

Theists take God to be a necessary being: one who could not possibly fail to exist, or, equivalently, one who exists in all possible worlds. No sense can be made of the idea that God stands outside of the set of worlds in order to select one for actualization. Since the possible worlds there are exhaust the way things could be, there simply is no vantage point, divine or otherwise, outside this set.

Second, while it is tempting to conflate world-actualization and creation, it is important to keep them distinct. Creation occurs when God causes it to be the case that some spatiotemporal entity is actual, but not every instance of world-actualization need involve this. Suppose that God creates nothing. If so, there still is an actual world. We might call it the bare world, since it is empty - save for whatever uncreated existents (such as numbers and God) it contains. God, of course, is responsible for the bare world's being actual, and so God has actualized it, without creating anything at all.

Third, God's actualizing a world need not mean that he determines each and every feature of the resulting world. Consider, for example, random processes. If a world features such processes, God causes it to be the case that they occur, but he does not (by definition) determine their outcome. ${ }^{14}$ Next, consider libertarian freedom. Many theists maintain that human beings have such freedom, and that the free choices of such creatures affect how the world unfolds (at least in worlds which feature such creatures). On this view, God and creatures jointly actualize a world: both play a role in determining which world is actual. God is responsible, inter alia, for a world's being the way it is prior to the introduction of creatures, and God is also responsible for the introduction of such creatures: all this properly counts as the product of God's worldactualizing activity. But when such creatures are introduced and act freely, they too help make it the case that one world rather than another is actual, and such determinations count as the product of their world-actualizing activity, not God's. The resulting world is partly the product of God's actions, and partly the product of creatures' actions. ${ }^{15}$

Finally, there is no need to suppose that God's causal activity in actualizing a world is limited to one act at the 'beginning' of that world. Some theists hold that God intervenes from time to time: on this view, God performs many world-actualizing actions throughout the history of the world being actualized. In addition, many theists hold that God's world-actualizing activity includes sustaining whatever is actual. This also suggests that God's world-actualizing activity does not occur 'all at once' at the outset of a world. ${ }^{16}$

\section{UNIVERSES AND MULTIVERSES}

A universe is a spatiotemporally-interrelated, causally-closed aggregate. ${ }^{17}$ It is sometimes taken for granted that there is a one-to-one correspondence between possible worlds and universes. But philosophers ${ }^{18}$ and scientists ${ }^{19}$ alike have suggested that this is unwarranted. Suppose they are right: worlds may then comprise more than one universe. In other words, at least one possible world is a multiverse. ${ }^{20}$

On this view, possible worlds are not physical containers for universes. ${ }^{21}$ Rather, a possible world is simply comprised of whatever universes there are in that world, together with whatever nonphysical entities there are. If a possible world comprises more than one universe, these universes may differ in many respects (e.g., different histories, different laws of nature), but they must be logically compossible: by definition, there can be no logical contradiction between different universes within one possible world. One consequence is that there can be no exact copies of universes within a multiverse. ${ }^{22}$ Another consequence is that there is no transuniverse identity of individuals within a multiverse: individuals in one universe can perhaps have counterparts in other universes, but no individual can exist in more than one universe within a single possible world. ${ }^{23}$ 
The axiological framework for possible worlds discussed in Sections 1 and 2 can now be applied, mutatis mutandis, to universes. Let's say that there is a set of universe-good-making properties, and a set of universe-bad-making properties, and that the axiological status of universes depends on how these are instantiated. ${ }^{24}$ Again for simplicity, let's assume necessitarianism concerning these properties, and commensurability and comparability concerning these universes. As we earlier restricted our attention to possible worlds actualizable by God, let's now restrict our attention to universes creatable by God. ${ }^{25}$ Finally, just as there are three candidate hierarchies of possible worlds (EOUW, IMUW, NUW) so too there are three candidate hierarchies of universes: either there is exactly one unsurpassable universe, or else there are none, or else there are infinitely-many. ${ }^{26}$

\section{Principles Governing Creation and SustenANCE, AND the Theistic Multiverse}

How does all this bear on theism? Paul Draper suggests that if theism is true, it's likely that the actual world is a multiverse - a rather large multiverse, in fact. (Note that he uses the term 'world' much as I do 'universe'.) Draper says that a multiverse is probable on theism

... not because there is any independent evidence ...but rather simply because a perfectly good God of limitless creative resources would be likely to create vastly many worlds [i.e. universes], including magnificent worlds of great perfection as well as good but essentially flawed worlds that are more in need of special providence ... For by creating valuable worlds, God adds to the excellence of reality and also provides for the expression of divine benevolence, divine justice, and other virtues. ${ }^{27}$

Several other philosophers have expressed similar sentiments. ${ }^{28}$ Pushed to their logical limit, these considerations suggest that an unsurpassably powerful, knowledgeable, and good deity will create every universe that is worth creating. I suspect that this way of thinking is motivated by a principle of plenitude 29 - perhaps something like this:

PP1 If a universe is creatable by an unsurpassable being, and worth creating (i.e., it has an axiological status that surpasses some objective threshold t), that being will create that universe. ${ }^{30}$

Of course, this principle has a corollary:

$\mathrm{PP} 2$ If a being fails to create any universe that is both worth creating and creatable (by that being), then that being is surpassable. ${ }^{31}$

If these principles are correct, an unsurpassable being will create all the universes worth creating.

As noted, God is thought not only to create whatever universes there are, but also to sustain them - to conserve them in existence. This suggests the following principle, and its subsequent corollary:

$\mathrm{PP}_{3}$ If a universe is sustainable by an unsurpassable being, and worth sustaining (i.e., it has an axiological status that surpasses some objective threshold $\mathrm{t}$ ), that being will sustain that universe.

$\mathrm{PP}_{4}$ If a being fails to sustain any universe that is both worth sustaining and sustainable (by that being), then that being is surpassable. 
According to principles $\mathrm{PP}_{1}-\mathrm{PP}_{4}$, if theism is true, all worthwhile universes are created and sustained by God. In addition, one might reasonably expect such a being to create and sustain only such universes. This idea is expressed by the following principles of restricted creation and sustenance, which parallel the principles just listed:

PR1 If a universe is not worthy of creation (i.e., it has an axiological status that fails to surpass some threshold $t$ ), an unsurpassable being will not create that universe.

PR2 If a being creates any universe that is unworthy of creation, then that being is surpassable. (Corollary of PR1.)

PR3 If a universe is not worthy of being sustained (i.e., it has an axiological status that fails to surpass some threshold t), an unsurpassable being will not sustain that universe. ${ }^{2}$

PR4 If a being sustains any universe that is unworthy of being sustained, then that being is surpassable. (Corollary of PR3.)

Space does not permit a detailed defence of these eight principles.33 In what follows, I assume that they enjoy prima facie plausibility, and I examine their import for the three hierarchies of worlds and the three respective objections to theism set out in Section 2.

These principles motivate careful consideration of a possible world I'll call the theistic multiverse (TM). In TM, God creates and sustains all and only those universes which are worth creating and sustaining. 34 Furthermore, TM comprises no other universes: since theism maintains that God is the creator and sustainer of all that is, it follows that in TM, no universes are created or sustained by any being other than God, and no universes lack a creator or sustainer.

\section{The Theistic Multiverse AND the Hierarchies OF Possible WORLDS}

I next consider how TM bears on the candidate hierarchies of possible worlds described in Section 2: NUW, IMUW, and EOUW. While only one of these can be correct, each was provisionally deemed a live possibility. But as we'll soon see, once TM is introduced into the discussion, two of these candidates can be eliminated.

Since TM is a possible world, and since on NUW every world is surpassable, it follows that on NUW, TM must be surpassable. But by what? TM comprises all and only those universes worth creating and sustaining. Any world which surpasses TM must be distinct from TM. Accordingly, any world which surpasses TM must either fail to comprise all, or only, those universes worth creating and sustaining (or both).

Consider the former case. A world which fails to comprise all the universes worth creating and sustaining seems incapable of surpassing TM. In fact, it seems surpassed by TM after all, TM comprises more worthy universes, and this is a powerful prima facie reason for thinking it better.35 And, in particular, if the principles of plenitude introduced above are plausible, then the theist cannot hold that any world (which fails to comprise all the universes worth creating and sustaining) can surpass TM, for according to $\mathrm{PP} 2$ and $\mathrm{PP} 4$, if God fails to create or sustain a universe worth creating and sustaining, God is surpassable.

Next, consider the latter case. A world which fails to comprise only universes worth creating and sustaining is a world which includes universes that are objectively unworthy of creation or sustenance: these have an overall axiological status lower than threshold t. Why would anyone think that a world with such universes could surpass TM? If anything, TM should 
be thought to surpass such a world, for the very reason that it lacks such unworthy universes. ${ }^{36}$ And, in particular, if the principles of restricted creation and sustenance introduced above are plausible, then the theist cannot hold that any world (which fails to comprise only universes worth creating and sustaining) can surpass TM, for according to PRC2 and PRC4, if God creates or sustains a universe which is unworthy of creation or sustenance, God is surpassable.

These considerations suggest that theists should hold that no world can surpass TM, in which case NUW is not a live option for the theist after all. And this, in turn, means that the theist needn't feel threatened by the argument for atheism (sketched in Section 2) that presupposes NUW.

If theists should hold that no world surpasses TM, then two alternatives remain: they should either hold that there are infinitely-many other unsurpassable worlds, or that TM is the unique best. In Section 2, I pointed out that IMUW is motivated by the claim that for any world $\mathrm{w}$ having axiological status $\mathrm{s}$, there are infinitely many trivially different variants of $\mathrm{w}$ which also have axiological status S. So, if IMUW is to remain a live option, we must consider whether there are any variants of TM that can plausibly be thought unsurpassable.

Any candidate for an unsurpassable world distinct from TM must comprise a different set of universes. TM comprises all and only those universes worth creating and sustaining, so again, any world distinct from TM must either not comprise all, or not only, the universes worth creating and sustaining (or both). If the principles introduced in Section 4 are plausible, then the theist simply cannot hold that any world (which fails to comprise all or only those universes worth creating and sustaining) can be equal in axiological status to TM. The reason is simple: according to $\mathrm{PP}_{2}$ and $\mathrm{PP}_{4}$, if God fails to create or sustain any universe worth creating and sustaining, God is surpassable, and according to PR2 and PR4, if God creates or sustains any universe which is unworthy of creation or sustenance, God is also surpassable. So IMUW is not a live option for the theist either. This suggests that the theist needn't feel threatened by the argument for atheism (sketched in Section 2) that presupposes IMUW.

In Section 2, I suggested that there are three candidate hierarchies of actualizable possible worlds. With the introduction of TM into the discussion, two have now been eliminated for the theist. It seems, then, that if the principles introduced in Section 4 are plausible, and if TM is logically possible, the theist should maintain that the actual world is TM, and that it is the unique best of all divinely-actualizable worlds. 37

\section{THE OBJ ECTION TO THEISM ON EOUW}

If this is correct, the theist should address the argument for atheism (sketched in Section 2) that presupposes EOUW..$^{8}$ On this hierarchy of worlds, it has been urged, a priori, that a perfect being would actualize the unique unsurpassable world and, a posteriori, that this expectation has not been met. In short, it is claimed that the actual world is surpassable, and that this disconfirms theism. This, of course, is a version of the problem of evil. In what follows, I'll simply grant the a priori claim, and concentrate on the a posteriori claim. $39 \mathrm{My}$ goal is neither to endorse it nor to refute it, but simply to set out how the discussion between the theist and the critic should now proceed.

Suppose I've succeeded in showing that, on theism, the one unique unsurpassable world is TM. How should the critic of theism argue that the actual world is not (or probably is not ${ }^{\circ}$ ) TM? She cannot defend this claim on the grounds that our universe is surpassable, for this is perfectly consistent with the actual world's being TM. In Section 3, I suggested that either there is exactly one unsurpassable universe, or else there are infinitely-many, or else there are none. In the third case, it should be no surprise to discover that our universe is surpassable, since every universe is surpassable. And in the other two cases, the surpassability of our universe (if established) cannot count against the actual world's being TM, since there is no particular reason to expect that we would find ourselves in an unsurpassable universe. ${ }^{41}$ 
The critic of theism, then, cannot show that the actual world is not TM in this way. To establish the a posteriori claim in the argument for atheism, she needs to show, not that our universe is surpassable, but that the actual world is surpassable. How might she do this? Recall that TM comprises all and only those universes worth creating and sustaining. To show that the actual world is surpassable, the critic of theism must argue either that the actual world fails to contain all the universes worth creating and sustaining, or that it fails to contain only those universes worth creating and sustaining (or both). It is difficult to see how one might attempt the former strategy, given that universes are spatiotemporally isolated. But the latter strategy is more promising: the critic of theism can argue that the actual world fails to contain only universes worth creating or sustaining - for example, by urging that our universe is not worth creating or sustaining.

It might be objected that this unreasonably forces the critic to rely on global claims claims about our whole universe - in constructing her argument. After all, many influential arguments for atheism involve local claims about suffering. (For example, William Rowe's influential 1979 argument concentrates on a specific instance of suffering - a fawn's slow, painful, death from injuries sustained in a lightning-induced forest fire - and argues that this counts against theism, since it should have been prevented by God.)

In response, I say that this distinction - while perhaps useful for classifying arguments from evil42 - does not matter here, since local claims about instances of suffering can be expressed as global claims about the features of a universe that contain such suffering. Thus, for example, the critic of theism might argue - globally, so to speak - that no universe is worth creating or sustaining if it contains any instances of gratuitous animal suffering, or any instances of uncompensated human suffering, or some other such feature. She might then argue - locally, so to speak - that our universe actually contains such features, and that accordingly, it is reasonable to believe that our universe is unworthy of creation or sustenance. The theist can then reply either by denying that the proffered characteristic would make a universe unworthy of creation or sustenance, or by denying that it is reasonable to think that this characteristic is actually present in our universe (or both).

A brief conclusion: if my arguments in Sections 1-6 are persuasive, theists should hold that the actual world is TM, and that it is the unique best of all divinely-actualizable possible worlds. But, as Section 7 shows, it remains to be seen whether this result counts for theism or against it. 43

\section{ACKNOWLEDGEMENTS}

I thank Paul Bali, N. Ballantyne, Jim Dianda, Peter Forrest, Luke Gelinas, David Hunter, Ed Luk, Jonathan Strand, Tom Talbott, and an anonymous Philosophical Studies referee for helpful comments on earlier drafts. Thanks also to Michael Almeida, Paul Draper, Hud Hudson, and Timothy O'Connor for sharing their prepublication work on this topic with me. I am grateful for the generous research support I received from Ryerson University, and from the Social Sciences and Humanities Research Council of Canada, in Fall 2006. 


\section{NOTES}

${ }^{1}$ Candidate WGMPs pick out a property held to be good-making. Traditional examples include: the presence of free moral agents in the world; the favourable balance of moral actions over immoral ones; the variety of phenomena in the world; and the simplicity of a world's governing laws.

${ }^{2}$ Candidate WBMPs typically appeal to the presence of unjustified evil or suffering in the world. On the Augustinian view according to which evil is in fact the absence of good (privatio boni), every WBMP would presumably refer to the absence of a WGMP. There may be such WBMPs, and there may also be WBMPs that are the contraries of WGMPs, and there may be other, different, WBMPs. I remain neutral on this; nothing turns on it for my purposes.

3 It may be that certain good-making properties cease to make worlds better past a certain point, or in certain combinations. The same goes, mutatis mutandis, for WBMPs. So, while the goodness of a world depends on its axiological properties, this dependency may not be simple.

4 The rival view, which I call contingentism, holds that the actual set of WGMPs and WBMPs might have had different members. One version of this view, called theological voluntarism, holds that God could have willed other properties to be good-making and bad-making than the ones that are so. For a discussion of this view, see Mann (1991, 253-8).

5 One might deny that all worlds can properly be evaluated with respect to a stable set of WGMPs and WBMPs: this is to hold that there are incommensurable pairs of worlds. (On this, see Mann (1991, 26873), and Grover (1998).) Alternatively, one might deny that all worlds can be compared. This can be done with or without appeal to incommensurability. Incommensurable worlds, of course, cannot be compared. But even if all worlds are commensurable, there might still be failures of comparability between worlds. For simplicity, I set these issues aside.

${ }^{6}$ For example, see Hoffman and Rosenkrantz $(2002,159)$ and Strickland (2006). Many more treat this as an epistemic possibility.

7 For example, suppose that $\mathrm{w}^{\prime}$ differs from $\mathrm{w}$ by having one more grain of sand on one beach than w does (and whatever is required for this, and whatever ensues from this). It seems reasonable to suppose that $\mathrm{w}$ and $\mathrm{w}^{\prime}$ are axiologically equivalent.

${ }^{8}$ Kretzmann (1991) offers a clear account of Aquinas' reasoning in this matter.

9 See, for example, Plantinga (1974b, 61); Schlesinger (1977); Forrest (1981); Reichenbach (1982, 121-9); and Swinburne $(1979,114-5)$.

${ }^{10}$ This, of course, is a version of the problem of evil. In response, some theists (notably, Robert Adams 1972) have rejected the a priori claim, while others - too many to mention here - have denied the a posteriori claim, or at least suggested that it has not been (or cannot be) justified.

A small qualification: while I here suggest that arguments for the surpassability of the actual world are a posteriori, Ian Wilks has offered a plausible counterexample: a priori introspection of one's own thoughts, desires, intentions, and the like, might well convince one that the actual world could be better. (In slogan form: male cogito ergo malum est.) In what follows, I ignore this special case. I also set aside other arguments for atheism that have been advanced on EOUW.

${ }^{11}$ David Blumenfeld $(1975,12)$. For more on this charge, see Blumenfeld $(1995,396)$ and Donald Turner (2003, 147). For a reply, see Strickland (2006).

${ }_{12}$ For arguments in this vein, see Grover (1988, 2003, 2004); Rowe (1993, 1994, 2002, 2004); Sobel (2004, 468-479); and Wielenberg (2004). 
${ }_{13}$ I here assume that there is no principled middle ground between claiming that there is exactly one unsurpassable world, and that there are infinitely-many.

14 Nor does God foreknow their outcome. This need not detract from divine omniscience, since it is plausible to hold that there are no truths to be known about (for example) the exact outcomes of random processes.

15 Molinism is the doctrine according to which there are unalterable contingent truths (known by God) about how libertarian-free creatures would act in various possible circumstances. On Molinism, God can control which libertarian-free creaturely actions occur without causing them: by actualizing the world in which his favoured creaturely actions obtain. This might be thought to favour the view that God determines every feature of a world in actualizing it, and this might be desirable for theists with a robust conception of divine sovereignty. But since theism does not entail Molinism, it remains correct to say that theism does not require the view that God determines every feature of a world in actualizing it. (Besides, Molinists needn't hold that God determines every feature a world in actualizing it - random processes serve as a counterexample.)

${ }^{16}$ For more on this, see Tom Talbott, "The Best of all Feasible Worlds" (unpublished manuscript). I remain neutral on whether divine world-actualizing activity is best construed to involve many actions, or one 'spread-out' action. I also remain neutral on whether divine world-actualizing activity is best understood to be timeless or temporal.

${ }^{17}$ John Leslie mentions four restrictions on something counting as a universe: (1) absence of causal contact with any other universe; (2) significantly unique in character; (3) large in size; and (4) unknowable from any other universe $(1989,66-67)$. The first seems to entail the fourth (but not viceversa, as Leslie notes); the second and third seem unnecessarily-restrictive for my purposes.

${ }^{18}$ Many philosophers have defended various versions of the multiverse. For a historical survey of manyuniverse hypotheses, see Munitz (1951). Those who take seriously the idea that theism suggests the multiverse include John McHarry (1978); Peter Forrest (1981, 1996); Michael Coughlan (1987); Donald Turner (2003); Paul Draper (2004); Hud Hudson (2006), and Timothy O’Connor (2008).

19 For good introductory surveys of arguments for the multiverse grounded in physics and cosmology, see Leslie (1989, Chapter 4) and Max Tegmark (2003).

${ }^{20}$ It will be worthwhile to distinguish this proposal from David Lewis' modal realism. For Lewis, possible worlds just are isolated, spatiotemporally-interrelated concrete objects. Lewis denies that one possible world can consist of two or more completely disconnected spacetimes - although he concedes that he would prefer not deny to this $(1986,71,74)$. On the strength of the considerations referred to above, I take seriously the thought that Lewis erred on this point. (For more on this, see Bricker 2001.) I make no further claims concerning the ontological status of possible worlds: I aim to be as neutral as possible between competing accounts.

${ }^{21}$ See Turner $(2003,148)$.

22 Given the Identity of Indiscernables, at any rate, this is impossible. (See McHarry 1978, 133.)

23 I here assume that bi-location is impossible, but of course this is controversial. Also, I should note that ruling out trans-universe identity does not itself rule out trans-world identity of individuals. But see note 34, below.

24 In note 3 I suggested that the dependency of the axiological status of a world on its WGMPs and WBMPs need not be simple. Similarly, the dependency of the axiological status of universes on the relevant properties need not be simple. One further point. Some WGMPs can equally be deemed universe- 
good-making properties. But not all: consider the property comprising many good universes. While this is a plausible world-good-making property, it cannot be a universe-good-making property.

25 While worlds are necessarily-existing states of affairs, and are hence actualized rather than created, universes are contingently-existing spatiotemporal entities, and are thus created rather than actualized.

${ }^{26}$ I remain neutral on this question. In contrast, Timothy O’Connor (2008, Section 5.1) claims that there are no unsurpassable universes.

${ }_{27}$ Draper 2004, 318-9. Although their cosmogonies are different, the same basic motivation drives Bruno and Kant:

I hold the universe to be infinite as a result of the infinite divine power; for I think it unworthy of divine goodness and power to have produced merely one finite world when it was able to bring into being an infinity of worlds (Bruno, as quoted in Munitz 1951, 244).

But what is at last the end of these systematic arrangements? Where shall creation itself cease? It is evident that in order to think of it as in proportion to the power of the Infinite being, it must have no limits at all ...the field of the revelation of the Divine attributes is as infinite as these attributes themselves (Kant 1755,138-9).

${ }^{28}$ See, for example, McHarry (1978, 133-4); Forrest (1996, 216-7); Turner (2003, 147-9); Hudson (2006, 166-171); and O’Connor (2008).

29 Turner $(2003,147)$ and Hick $(1978,72)$ attribute this term to Arthur Lovejoy. Lovejoy has in mind “...not only the thesis that the [actual world] is a plenum formarum in which the range of conceivable diversity of kinds of living things is exhaustively exemplified, but also any other deductions from the assumption that no genuine potentiality of being can remain unfulfilled, that the extent and abundance of the creation must be as great as the possibility of existence and commensurate with the productive capacity of a 'perfect' and inexhaustible Source, and that the world is better, the more things it contains" $(1936,52)$. Clearly, the principles I suggest are more restricted.

$3^{0}$ This threshold would be difficult to specify, but could presumably be expressed in the language of WGMPs and WBMPs. Van Inwagen (2006, 95-112) offers an argument that could be deployed to suggest that talk of such a threshold is incoherent. Van Inwagen's argument is not without its critics, however. See, for example, Jeff Jordan (2003).

O'Connor (2008, Section 5.1) expresses doubts about the principle of plenitude, favouring instead a weaker principle which requires God to create at least one universe of every significant type or kind, above some threshold. He does not, however, explain what he means by 'type' or 'kind', nor does he explain what is wrong with the principle of plenitude.

${ }^{31}$ This principle is modeled on Rowe's notorious "Principle B" (2004, 91). It can be seen as the conjunction of two claims:

PP2a: If a being fails to create any universe that is both creatable and worth creating, then ceteris paribus, it is possible for that being to have performed a better world-actualizing action.

PP2b: If it is possible for a being to have performed a better world-actualizing action, then, ceteris paribus, it is possible for that being to have been better.

Critics, of course, might attack either claim.

$3^{2}$ This sounds more dramatic than it is. God can fail to sustain a universe in a variety of ways. One is, of course, to destroy it altogether. Another is to introduce something into that universe that would otherwise have been lacking, and still another is to remove something from that universe that would otherwise have been present. 
33 Critics might allege that they are implausible in the divine case, or they might insist that they are unmotivated (or defeated) by reflection on cases of human creation and sustenance.

34 Tom Talbott and Peter van Inwagen have independently suggested that I cannot reasonably claim that TM comprises all universes worth creating and sustaining. Their objection can be put as follows. Consider some person, $\mathrm{P}$, who exists in a universe, $\mathrm{U}$, that is worthy of creation and sustenance. TM includes $\mathrm{U}$, and also includes, inter alia, all other universes which both (i) contain P's counterparts, and (ii) are worthy of creation and sustenance. So far, so good. But, according to Talbott and van Inwagen, there are still other universes worthy of creation and sustenance which include P herself, and not just P's counterparts. If any such universe is possible, then it exists in a possible world - but it cannot exist in TM, on my view.

Accordingly, TM fails to contain all universes worth creating and sustaining. My response is developed in "Theism and Modal Collapse", where I argue - on quite independent grounds - that if theism is true, TM is the only possible world that there is. If this surprising view is correct, then a fortiori no individual can inhabit multiple worlds - and the Talbott / van Inwagen objection fails.

35 Here is an objection. Suppose (for simplicity) that there are exactly 1000 universes worthy of creation and sustenance in TM, each with a distinct axiological status, and that they are numbered in ascending axiological order: $\{1,2,3 \ldots 1000\}$. Compare that to $\mathrm{TM}^{+}$: a world which comprises only the following universes: $\{101,102,103 \ldots 1000\}$. The universes in $\mathrm{TM}^{+}$have a higher average axiological status than the universes in $\mathrm{TM}$, so one might think that $\mathrm{TM}^{+}$surpasses TM. But while $\mathrm{TM}^{+}$comprises only universes worth creating, it does not comprise all universes worth creating. So it is natural to think that $\mathrm{TM}^{+}$could be improved by the addition of universes $\{1-100\}$. But, of course, this is just to describe TM, and so TM surpasses $\mathrm{TM}^{+}$. For other arguments in this spirit, see Turner $(2003,151)$ and Draper $(2004,319)$.

${ }^{36}$ One might try to object that the creation of universes which are unworthy of creation might somehow serve to make the entire world better that it otherwise would be (as the addition of some dissonance might serve to make a musical composition more harmonious overall). But it's difficult to see how such an objection can be sustained, given that universes are causally isolated. Nor, in my view, can aesthetic considerations plausibly be brought to bear in this context.

37 That theism requires a multiverse is perhaps surprising, since the multiverse is so often invoked in criticisms of the fine-tuning argument for theism. For a good survey of such criticisms and replies, see the introduction to Neil Manson (2003).

${ }^{8}$ There are, of course, other arguments for atheism on this view, but I will focus on this one, since it is undoubtedly the most influential.

39 The most influential criticism of the a priori claim is Adams (1972), but in my view, this criticism has been shown a failure by several authors - most recently, by Weilenberg (2004) and Rowe (2004, Chapter 5).

40 Arguments from evil are sometimes divided into the more ambitious - called deductive or logical which purport to show that God does not exist, and the more modest - called inductive or evidential which purport to show that, probably, God does not exist. In what follows, I will not insert parenthetical qualifications like this to cover the latter, but what I say should be assumed to apply to them as well.

${ }^{41}$ For similar remarks, see Draper $(2004,313)$ and O'Connor (2008, Sections 5.1. and 5.3.1).

${ }^{42}$ See van Inwagen $(2006,8)$.

43 To my knowledge, no philosopher has yet explicitly criticized "multiverse theism" by appeal to evil. But, as I've suggested, claims in typical arguments from evil can be offered as reasons for thinking that our universe is not worthy of creation or sustenance, and thereby deployed in arguments against multiverse theism. 
A handful of philosophers have defended theism against traditional arguments from evil by appeal to the multiverse. McHarry (1978) claims that a response based on the multiverse can solve the problem of evil. Turner (2004) suggests that it is a partial solution, and O'Connor (2008, Section 5.3.1) sees prospects for theodicy here. More elaborate multiverse-based responses can be found in Forrest (1996) and Hudson (2006). Draper (2004) is the only philosopher to criticize the multiverse-based response to the problem of evil, though he does not directly address these authors. Space does not permit consideration of these rather varied positions.

\section{REFERENCES}

Adams, R. (1972) “Must God Create the Best?”, Philosophical Review 81: 317-332.

Blumenfeld, D. (1975) “Is the Best Possible World Possible?”, J ournal of Philosophy 84: 163177.

(1995) "Perfection and Happiness in the Best Possible World", in Jolley, N. [Ed.]

Cambridge Companion to Leibniz, Cambridge: Cambridge University Press.

Bricker, P. (2001) "Island Universes and the Analysis of Modality", in G. Preyer, F. Siebelt [Eds.], Reality and Humean Supervenience: Essays on the Philosophy of David Lewis, Rowman and Littlefield.

Coughlan, M.J. (1987) “Must God Create Only the Best Possible World?”, Sophia 26: 15-19.

Draper, P. (2004) "Cosmic Fine-Tuning and Terrestrial Suffering: Parallel Problems for Naturalism and Theism”, American Philosophical Quarterly 41: 311-321.

Forrest, P. (1981) “The Problem of Evil: Two Neglected Defences”, Sophia 20: 49-54.

(1996) “A Speculative Understanding of Evil”, Chapter 8 of God Without the Supernatural, Ithaca: Cornell University Press, 213-236.

Grover, S. (1988) “Why only the Best is Good Enough”, Analysis 48: 224. (1998) "Incommensurability and the Best of All Possible Worlds", The Monist 81: 648667. (2003) "This World, 'Adams Worlds'. and the Best of All Possible Worlds”, Religious Studies 39: 145-163. (2004) "Rival Creator Arguments and the Best of all Possible Worlds", Sophia 43 (2004): 101-114.

Hick, J. (1978) Evil and the God of Love [Revised Edition], New York: Harper and Row.

Hudson, H. (2006) "Hyperspace and Theism”, in The Metaphysics of Hyperspace, Oxford: Oxford University Press, 163-181.

Jordan, J. (2003) “Evil and Van Inwagen”, Faith and Philosophy 20: 236-239. 
Kant, I. (1755) Universal Natural History and Theory of the Heavens [Hastie, W., Trans.], Ann Arbour: University of Michigan Press, 1969.

Kraay, K. (unpublished manuscript) “Theism and Modal Collapse”, available at www.ryerson.ca/ kraay/.

Kretzmann, N. (1991) “A Particular Problem of Creation”, in MacDonald, S. [Ed.] Being and Goodness Ithaca: Cornell University Press, 229-249.

Leslie, J. (1989) Universes, New York: Routledge.

Lewis, D. (1986) On the Plurality of Worlds, Cambridge: Blackwell.

Lovejoy, A.O. (1936) The Great Chain of Being, New York: Harper and Row.

Mann, W. (1991) “The Best of all Possible Worlds”, in S.J. MacDonald [Ed.], Being and Goodness: The Concept of God in Metaphysics and Philosophical Theology. Ithaca: Cornell University Press, 251-277.

Manson, N. (2003) God and Design: The Teleological Argument and Modern Science, New York: Routledge.

McHarry, J.D. (1978) “A Theodicy”, Analysis 38: 132-134.

Munitz, M.K. (1951) “One Universe or Many?”, J ournal of the History of Ideas 12: 231-255

O’Connor, T. (2008) "The Scope of Contingency”, Chapter 5 of The Necessary Shape of Contingency: Theism and Ultimate Explanation, Melbourne: Wiley-Blackwell.

Plantinga, A. (1974a) The Nature of Necessity, Oxford: Clarendon Press.

(1974b) God, Freedom, and Evil. Grand Rapids: Eerdmans.

Reichenbach, B. (1982) Evil and a Good God. New York: Fordham University Press.

Rowe, W. (1993) “The Problem of Divine Perfection and Freedom” in E. Stump [Ed.], Reasoned Faith, Ithaca: Cornell University Press, 223-233. (1994) “The Problem of No Best World”, Faith and Philosophy 11: 269-271.

“Can God be Free?”, Faith and Philosophy 19 (2002): 405-424. (2004) Can God Be Free?, Oxford: Oxford University Press.

Schlesinger, G. (1977) Religion and Scientific Method, Dordrecht: Reidel.

Sobel, H. (2004) Logic and Theism: Arguments for and Against Beliefs in God, Cambridge: Cambridge University Press.

Strickland, L. (2006) “God's Problem of Multiple Choice”, Religious Studies 42: 141-157. 
Swinburne, R. (1979) The Existence of God. Oxford: Clarendon Press.

Talbot, T. (unpublished manuscript) "The Best of All Feasible Worlds".

Tegmark, M. (2003) “Parallel Universes”, Scientific American 288: 41-53.

Turner, D. (2003) “The Many-Universes Solution to the Problem of Evil”, in Gale, R., and Pruss, A. [Eds.], The Existence of God, International Research Library of Philosophy, Aldershof: Ashgate, 2003, 1-17.

van Inwagen, P. (2006) The Problem of Evil, Oxford: Oxford University Press.

Wielenberg, E. (2004) “A Morally Unsurpassable God Must Create the Best”, Religious Studies 40: $43-62$. 